\title{
Dietary Patterns and Obesity among Pre- Adolescents in Nairobi, Kenya
}

\author{
Janet Kajuju Malla $^{1}$, Prof. Judith Waudo ${ }^{2}$, Dr. Ciriaka T. Kithinji (Late) ${ }^{3}$ \\ ${ }^{I}$ (Department of Human Nutrition and Dietetics, Technical University of Kenya, P.O.Box 52428-00200 Nairobi- \\ Kenya) \\ ${ }^{2,3}$ (Department of Food Nutrition and Dietetics, Kenyatta University P.O.Box 43844 -00100 Nairobi- Kenya)
}

\begin{abstract}
Food continues to be a major factor in the development of the whole person throughout the growing years. Food becomes a means of communication; it is intimately associated with the emotions; and its acceptance or rejection is highly personal. The pattern for obesity is often set in infancy where sometimes overeating becomes a habit. Continued nibbling of food between meals and night eating syndrome where patients suffer from a voracious appetite after the usual evening meal is also associated with obesity. This was a descriptive study aimed at investigating the relationship between dietary patterns and obesity among Preadolescents. Systematic random sampling was used to select pupils from two day private primary schools in Nairobi making a sample of 120 pupils. Quantitative data were analyzed by computer through the use of Statistical Package for Social Sciences (SPSS). Linear regression analysis was used to test the hypothesis. The study showed a significant relationship between dietary patterns of the pre-adolescents and obesity. Regression Analysis results showed that eating food three times a day and eating any time were positively correlated with obesity. Skipping meals was significant at $(p<0.05)$ significant level.
\end{abstract}

Keywords: Body Mass Index (BMI), Dietary Patterns, Obesity, Overweight, Snacking

\section{Introduction}

The Childhood obesity is the most common and serious nutritional condition in the Western industrialized world. Studies available indicate that one third or more of the infants are obese [1]. In fact studies show that $80 \%$ of the obese adolescents become obese adults [2]. Evidence suggests that over feeding of infants and young children may lead to the production of increased number of fat cells in the body that predispose the individual to obesity in adulthood [3].

The problem of over nutrition is one of the most widespread nutrition disorders among children in the United States. Obesity affects as many as $27 \%$ of children in the U.S, and the prevalence of obesity among 6-11 year old children had increased to 54\% in the last twenty years [4]. A similar trend has been observed in Japan; the frequency of obese school children aged between 6-14 years increased from 5\% to $10 \%$ and that of extremely obese children from $1 \%$ to $2 \%$ during the last twenty years [5]. The pattern for obesity is often set in infancy when the mother overfeeds the baby in the erroneous belief that a 'fat baby is healthy baby'. Sometimes overeating becomes a habit [3]. According to [6], continued nibbling of food between meals and night eating syndrome where patients suffer from a voracious appetite after the usual evening meal is also associated with obesity. [7], further points out that a high intake of energy involving excessive consumption of refined sweets, sugars, refined foods and fats is a common practice that predisposes the individual to obesity.

Culture affects both food intake and physical activity patterns. Cultural behaviors and beliefs are learned in childhood, are often deeply held, and are seldom questioned by adults who pass this knowledge to their offspring's. Cultural factors are among the strongest determinants of food choice. These include peer group pressures, social conventions, religious practices, and the status value afforded to the different foods, the influence of other members of the household and individual lifestyles. These are often adhering to peer pressure by selection of high-fat food choices [8].

The various communication media, including Television, Radio, and print play a major role in information dissemination in modern consumer's societies. They are part of informal education and both reflect and influence public attitudes. However, the money spent on promoting high fat/energy- dense food is considerably more than that spent on promoting healthier foods. For example, $\$ 80$ million was spent on promoting chocolate consumption in the UK in 1992 compared to only \$3 million spent on promoting fruit and vegetable [9]. The media provide information on new and existing foods to consumers and have a pervasive influence on food choice; they have clearly been influential in changing dietary patterns over recent decades. Television in particular plays a major role in informing and influencing children. This development may have a negative effect. For example, 91\% of foods advertised during peak children's viewing time in U.S.A., and UK, were high in fat, sugar and carbohydrates. This does influence the eating habits and selection of food in children [10]. 
Junk foods, eating foods with a lot of fats and snacking are the common practices that predispose the children to obesity. According to [8], studies of dietary intake and weight in both men and women indicate that the average BMI, and the proportion of those overweight and obese decrease as total Calories intake increases, largely as result of differences in added sugar intake. However BMI increases as the proportion of fat in the diet increases, regardless of the total level of energy intake. Dietary fat also contributes to overeating. The satiating effect of carbohydrates is greater than that of fats. This therefore makes it easier for individuals to over consume fat containing diets without reaching satiety. Advances in food technology have also contributed to the consumption of diets which are increasingly dependent on processed foods. It is now possible to produce food products with an almost limitless combination of taste textural quality and nutrient content [11]. Although it may be argued that "fast foods" have been available for centuries, the foods provided tended to be those of traditional diet and culture. Today fast foods and snacks tend to be universal in nature and are high in fat, low in complex carbohydrates and energy dense. It is widely perceived that obesity has increased in industrial societies as families turn away from home-prepared meals and utilize more fast or take-away foods [12].

\section{Materials And Methods}

A descriptive study was used whereby obesity was determined by calculating the Body mass Index (BMI). Weights and heights of children were taken. Questionnaires were used as the key method of data collection hence able to reach a large number of respondents within a short period of time. The sample consisted of two private primary schools in Nairobi, with each providing a sample of sixty students $(n=60)$. In total, the sample consisted of one hundred and twenty $(\mathrm{N}=120)$ respondents. The target Population comprised of children aged between 11 years and 12 years of age. The study was carried out in day private primary schools. Day schools were studied because children usually go home and some carry packed lunch to school therefore influencing their dietary patterns.

Respondents were selected through Systematic Random Sampling. The sample comprised of 60 male and 60 female pupils attending day private primary schools in Nairobi, Kenya giving a total of 120 respondents. Another 16 respondents both male and female were purposively selected to form a subset for observation. Overweight respondents were the ones to be included in the observation schedule hence they were purposively selected after obtaining their weight and height. A questionnaire and an observation check- list were used to gather information on demographic characteristics, dietary patterns of the respondents. The instruments were pre-tested on six (6) pupils, three females, three males, one head-teacher, and one class teacher from a different school. Pre-testing was done to ensure refinement of the validity of the instruments used. Necessary revisions of the instruments were done after the Pre-testing. Data were analyzed using SPSS Computer package. Descriptive measures were used to organize and describe characteristics of the sample. These were mainly frequencies and percentages. Linear regression analysis was used to test the hypothesis. Qualitative data, in form of words, was transformed into notes by coding data into common themes. Patterns were then consolidated to form concepts. Relationships between various concepts were established. Inferences and conclusions were then drawn from the findings.

\subsection{Demographic Characteristics of Respondents}

\section{Results}

\subsubsection{Educational Level of Respondents' Parents}

Education level has an influence on the feeding habits because choice of food will largely depend on one's nutritional knowledge and these patterns determine obesity.

The respondent's parents had varied levels of education ranging from primary to University. More males $(39.2 \%)$ than females $(24.2 \%)$ had university level of education.

Table 1 Parents Education Level by gender

\begin{tabular}{|l|l|l|l|l|}
\hline \multirow{2}{*}{ Education level } & Male & Female \\
\cline { 2 - 6 } & $\mathrm{N}$ & $\mathrm{N}$ & \multicolumn{2}{l}{$\%$} \\
\hline University level & 47 & 39.2 & 29 & 49.1 \\
\hline College level & 44 & 36.7 & 59 & 18.3 \\
\hline Secondary level & 28 & 23.3 & 22 & 6.7 \\
\hline Primary level & 1 & 0.8 & 8 & 1.7 \\
\hline No Formal Education & 0 & 0.0 & 2 & $\mathbf{1 0 0 . 0}$ \\
\hline Total & $\mathbf{1 2 0}$ & $\mathbf{1 0 0 . 0}$ & $\mathbf{1 2 0}$ & \\
\hline
\end{tabular}

Incidentally, more females $(49.1 \%)$ than males $(36.7 \%)$ had college level of education. There were also more females $(6.7 \%)$ than males $(0.8 \%)$ who had primary level of education. There were no males without formal education but $1.7 \%$ of the females had no formal education. This could be attributed to past emphasis on educating males rather than females. 


\subsubsection{Weight of Respondents}

One of the indicators of obesity is weight therefore it was necessary to find out the weight of the respondents. The highest category of weight was $51-65 \mathrm{Kg}$, where $(55 \%)$ of the respondents fell. There were more males (41) than females (25) in this category and this could be due to the fact that men have a higher basal metabolic rate than women so they tend to eat a lot at this age. The least represented was $66-80 \mathrm{~kg}$ with $20 \%$ respondents.

Table 2: Weight of respondents

\begin{tabular}{|l|l|l|l|l|}
\hline Weight $\mathbf{( K g )}$ & Male & Female & Total & \% \\
\hline $36-50$ & 7 & 23 & 30 & 25.0 \\
\hline $51-65 \mathrm{~kg}$ & 42 & 25 & 67 & 55.8 \\
\hline $66-80$ & 10 & 11 & 21 & 17.5 \\
\hline 80 and over & 1 & 1 & 2 & 1.7 \\
\hline TOTAL & $\mathbf{6 0}$ & $\mathbf{6 0}$ & $\mathbf{1 2 0}$ & $\mathbf{1 0 0 . 0 0}$ \\
\hline
\end{tabular}

\subsubsection{Height of respondents}

The height of respondents ranged between $125 \mathrm{~cm}-169 \mathrm{~cm}$. The highest category reported was $140-154 \mathrm{~cm}$ with a frequency of $69.2 \%$. Twenty per cent $(20 \%)$ had a height range of $155-169 \mathrm{~cm}$ and a small percentage $(10.8 \%)$ had a height range of $125-139 \mathrm{~cm}$. The mean height was $147 \mathrm{~cm}$.

Table 3: Height of respondents

\begin{tabular}{|l|l|l|l|l|}
\hline Height $(\mathbf{C m})$ & Male & Female & Total & \% \\
\hline $125-139$ & 8 & 5 & 13 & 10.8 \\
\hline $140-154$ & 36 & 47 & 83 & 69.2 \\
\hline $155-169$ & 16 & 8 & 24 & 20.0 \\
\hline TOTAL & $\mathbf{6 0}$ & $\mathbf{6 0}$ & $\mathbf{1 2 0}$ & $\mathbf{1 0 0 . 0}$ \\
\hline
\end{tabular}

\subsection{Dietary Patterns of the respondents}

\subsubsection{Number of Times respondents ate in a day}

Table 4 shows that fifty percent $(50 \%)$ of the respondents consumed food at any time of the day while $40 \%$ ate three times in a day, $6.6 \%$ ate twice a day and $1.7 \%$ ate once a day.

Table 4: Number of Times the Respondents Ate in a Day

\begin{tabular}{|l|l|l|l|l|}
\hline No. of eating times & Male & Female & Total & \% \\
\hline Once & 1 & 1 & 2 & 1.7 \\
\hline Twice & 3 & 5 & 8 & 6.6 \\
\hline Thrice & 16 & 32 & 48 & 40.0 \\
\hline Any time of the day & 39 & 21 & 60 & 50.0 \\
\hline No response & 1 & 1 & 2 & 1.7 \\
\hline Total & $\mathbf{6 0}$ & $\mathbf{6 0}$ & $\mathbf{1 2 0}$ & $\mathbf{1 0 0 . 0}$ \\
\hline
\end{tabular}

\subsubsection{Meals skipped by respondents}

It was necessary to find out if any respondents skip meals in order to determine if there was a relationship between eating habits and obesity.A majority of the respondents (77.5\%) did not skip any meal of the day, only a small percentage (22.5\%) skipped breakfast, lunch or supper (Table 5). Therefore due to availability of money food can be purchased and eaten at any time of the day hence no meal was skipped.

Table 5: Meals skipped by respondents

\begin{tabular}{|l|l|l|l|l|}
\hline Meal Skipped & Male & Female & Total & \% \\
\hline Breakfast & 2 & 3 & 5 & 4.2 \\
\hline Lunch & 2 & 8 & 10 & 8.3 \\
\hline Supper & 5 & 7 & 12 & 10.0 \\
\hline None & 51 & 42 & 93 & 77.5 \\
\hline Total & $\mathbf{6 0}$ & $\mathbf{6 0}$ & $\mathbf{1 2 0}$ & $\mathbf{1 0 0 . 0}$ \\
\hline
\end{tabular}

\subsubsection{Type of Snacks Consumed by Respondents}

There were a variety of snacks, which were consumed by the respondents in between the main meals throughout the day as shown in Table 6 . The snacks that were highly consumed on a daily basis were sausages where ninety five percent (95\%) consumed at least one sausage, $94.2 \%$ consumed two glasses juice/soda, $89.2 \%$ consumed one packet of chips and $82 \%$ consumed more than two cookies, while $71.7 \%$ consumed more than half a packet of crisps and $52.5 \%$ consumed one packet of popcorns. Ninety five percent (95\%) did not consume any fruit or fruit salad. This finding can be attributed to the fact that most children prefer drinking soda or commercial juices than the fresh fruit juice. The time required for preparation of the fruit juice or salad could be 
limited as these are day scholars hence they have to get prepared for school early in the morning. Media also has an influence due to the advertising done on commercial juices and sodas hence influencing the children's choice.

Table 6: Type of snack consumed by Pre - adolescents in Nairobi

\begin{tabular}{|l|l|l|l|}
\hline Type of snack* & $\mathrm{N}$ & $\%$ & Quantity per day \\
\hline Chocolates & 14 & 11.7 & 1 bar \\
\hline Chips & 107 & 89.2 & $1 \mathrm{pkt}$ \\
\hline Sausage & 114 & 95.0 & 1 \\
\hline Juice/Soda & 113 & 94.2 & 2 glasses \\
\hline Cookies & 99 & 82.5 & More than two \\
\hline Potato Crisps & 86 & 71.7 & $1 / 2 \mathrm{pkt}$ \\
\hline Popcorns & 63 & 52.5 & $1 \mathrm{pkt}$ \\
\hline Mandazi/cakes/bread & 24 & 20.0 & $2 \mathrm{pieces}$ \\
\hline Sandwiches/hotdogs & 42 & 35.0 & Three pieces \\
\hline Fruit/Fruit salad & 6 & 5.0 & 1 bowl \\
\hline Meat/chicken & 42 & 35.0 & $1 \mathrm{piece}$ \\
\hline Sweet/gum & 30 & 25.0 & Many \\
\hline Ice cream/yoghurt & 53 & 44.1 & 1 bowl \\
\hline Peanuts & 66 & 55.0 & $1 / 2$ a packet \\
\hline
\end{tabular}

*Multiple responses are allowed.

\subsubsection{Respondents who carried packed Lunch}

It was necessary to find out the percentage number of respondents who carried or did not carry lunch to school because this would their other sources of lunch. Table 7 clearly shows that $46.6 \%$ of the respondents did not carry lunch to school and this could be because they were given money to buy lunch at school or it was paid for in advance. Further questioning revealed that fifty (50\%) of the respondents carried packed lunch to school while only a small percentage $(1.7 \%)$ carried lunch sometimes. This implies that some pupils carried lunch and were given pocket money at the same time.

Table 7: The number of respondents who carried lunch to school

\begin{tabular}{|l|l|l|}
\hline Response & N & \% \\
\hline No & 56 & 46.6 \\
\hline Yes & 60 & 50.0 \\
\hline Sometimes & 2 & 1.7 \\
\hline No response & 2 & 1.7 \\
\hline TOTAL & $\mathbf{1 2 0}$ & $\mathbf{1 0 0 . 0}$ \\
\hline
\end{tabular}

\subsubsection{Food Items carried to school}

Among the food items carried to school were sausages where $50 \%$ of the respondents carried two sausages, $59.2 \%$ carrying between one and two packets of chips. Fruits or fruit salad had the lowest percentage with only $5 \%$ of the respondents including it in the packed lunch (Table 8). Reasons given for poor intake of fruits or fruit salad were:

i. That they were never packed for them and when packed whole they would get mashy, e.g., bananas;

ii. The bag would be too bulky if they carried two lunch boxes because fruits/fruit salad cannot be mixed with other savoury foods.

Table 8: The types of foods carried to school as packed lunch

\begin{tabular}{|l|l|l|l|}
\hline Type of food* & $\mathrm{N}$ & $\%$ & Quantity \\
\hline Chips & 71 & 59.2 & $1-2$ pkts \\
\hline Sausages & 60 & 50.0 & One \\
\hline Sandwich/hamburger & 65 & 54.1 & $2-3$ \\
\hline Rice/stew & 26 & 21.7 & 1 plate \\
\hline Samosa & 79 & 65.8 & $2-3$ pieces \\
\hline Vegetables & 4 & 3.3 & 1 bowl \\
\hline Fruits/Fruit salad & 6 & 5.0 & 1 bowl \\
\hline
\end{tabular}

\section{*Multiple responses allowed}

Vegetables were also found not to be a delicacy for many respondents as they pointed out that they were not tasty and they would also add to the bulkiness when carrying the school bag. Items that were easy to carry and easy to eat by hand were preferred, for example chips, sausages and sandwiches (Table 6). 


\subsection{Food consumption frequency}

The frequency consumption of certain foods may reveal the extent to which an individual consumes a balanced meal. The meals consumed by the respondents were assessed in order to determine the nutrients that the meals provided, their sources and how often they were consumed. The study showed the number of regular meals the respondents reported to have eaten in a week. The meals were scored under the daily, weekly, monthly, never and any other categories depending on how often the respondents consumed them. The frequency of the food intake is illustrated in Table 9.

Table 9 Frequency of Food Consumption by the Respondents

\begin{tabular}{|c|c|c|c|c|c|}
\hline Food Type* & Daily & Weekly \% & Monthly \% & Never $\%$ & Any other \% \\
\hline \multicolumn{6}{|l|}{ Proteins } \\
\hline Fish & 1.7 & 45.8 & 31.7 & 5.8 & 15.0 \\
\hline Eggs & 17.4 & 52.5 & 14.2 & 5.0 & 10.9 \\
\hline Milk & 77.5 & 10.0 & 3.3 & 2.5 & 6.7 \\
\hline Chicken & 10.8 & 64.2 & 12.5 & 3.3 & 9.2 \\
\hline Beef & 35.0 & 41.7 & 9.2 & 5.8 & 8.3 \\
\hline Beans & 7.5 & 41.7 & 35.8 & 2.5 & 12.5 \\
\hline $\begin{array}{l}\text { Carbohydrates } \\
\text { Chips }\end{array}$ & Carbohydrates & 64.2 & 9.1 & 0.0 & 4.2 \\
\hline Ugali & 9.2 & 53.3 & 19.2 & 2.5 & 15.8 \\
\hline Rice & 38.3 & 51.7 & 6.7 & 0.0 & 3.4 \\
\hline Chapatis & 23.3 & 50.8 & 18.4 & 0.8 & 6.7 \\
\hline Yams & 0.8 & 11.7 & 36.7 & 30.0 & 20.8 \\
\hline Arrow roots & 0.0 & 5.0 & 42.5 & 28.3 & 24.2 \\
\hline Mashed potatoes & 5.8 & 34.1 & 43.4 & 5.0 & 11.7 \\
\hline \multicolumn{6}{|l|}{ Fat } \\
\hline Butter/margarine & 65.0 & 20.8 & 6.7 & 2.5 & 5.0 \\
\hline Peanut butter & 33.3 & 21.7 & 20.8 & 7.5 & 16.7 \\
\hline Cheese & 32.5 & 27.5 & 20.8 & 9.2 & 10.0 \\
\hline Cream & 17.0 & 27.5 & 28.0 & 10.2 & 17.5 \\
\hline \multicolumn{6}{|l|}{ Fruits } \\
\hline Oranges & 44.2 & 38.3 & 9.2 & 0.8 & 7.5 \\
\hline Bananas & 47.5 & 36.7 & 7.5 & 0.8 & 7.5 \\
\hline Avocados & 13.3 & 32.5 & 21.7 & 13.3 & 19.2 \\
\hline Pawpaw & 32.5 & 23.3 & 19.2 & 8.3 & 16.7 \\
\hline Passion & 28.6 & 31.7 & 22.7 & 4.4 & 12.6 \\
\hline Pineapple & 38.6 & 34.2 & 17.5 & 1.7 & 8.0 \\
\hline \multicolumn{6}{|l|}{ Vegetables } \\
\hline Cabbage & 32.6 & 50.9 & 10.8 & 0.8 & 4.9 \\
\hline Spinach & 30.0 & 50.0 & 15.0 & 0.8 & 4.2 \\
\hline Sukumawiki & 22.5 & 50.9 & 17.5 & 2.5 & 6.6 \\
\hline Cowpea(leaves) & 6.6 & 21.7 & 25.0 & 22.5 & 24.2 \\
\hline Tomatoes & 68.3 & 23.3 & 5.0 & 0.0 & 3.0 \\
\hline
\end{tabular}

*Multiple responses allowed

\subsubsection{Frequency Consumption of proteins}

The findings from table 9 revealed that milk was the most frequently consumed protein under the foods consumed daily $(77.5 \%)$ and this could be because most respondents indicated consuming tea and milo for breakfast and at 4 O'clock. Beef was the second most frequently consumed $(35.0 \%)$ under the same category this is because beef is cheap compared to the other proteins. Chicken was consumed by $(64.2 \%)$ of respondents on a weekly basis and this could be due to the fact that chicken is expensive therefore cannot be afforded on a daily basis. Eggs came second in the weekly category with $(52.5 \%)$ of the respondents. Other sources of protein such as beans and fish were consumed more on a weekly basis than on daily basis by the respondents and this could be due to variation in tastes and preferences of the respondents. 
Fig 1: A Bar Graph Showing Frequency Consumption of Protein by Respondents

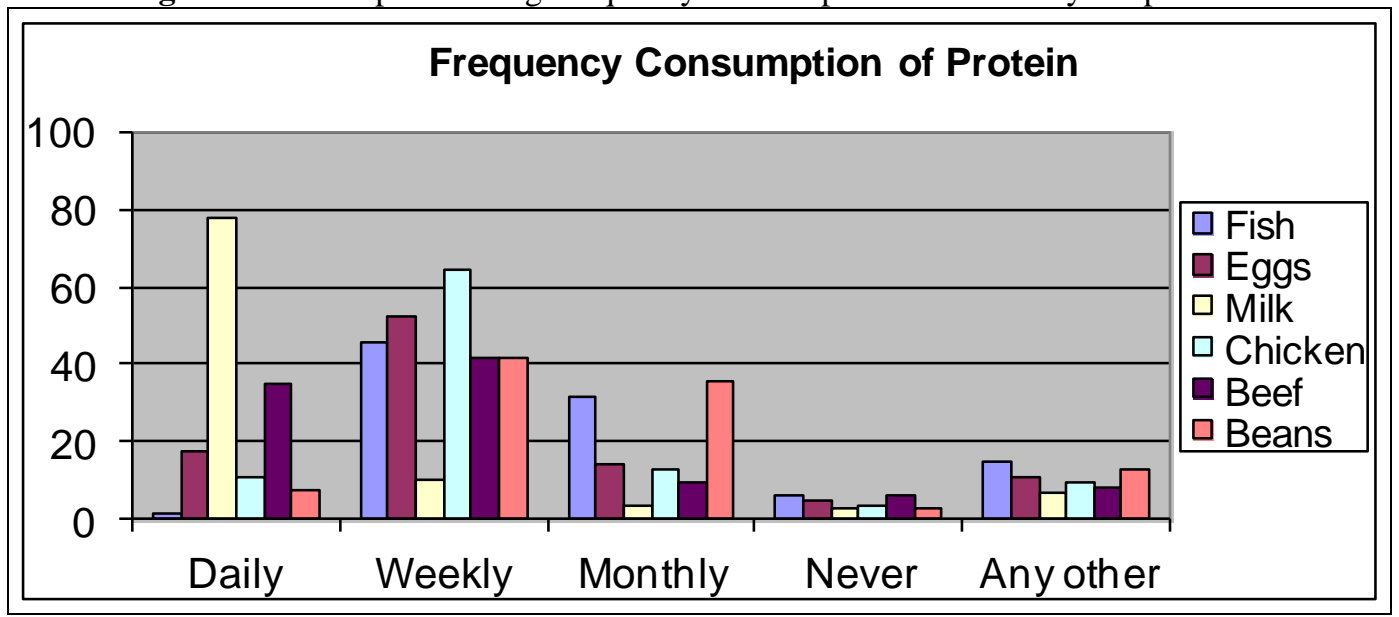

\subsubsection{Frequency Consumption of carbohydrates}

In the carbohydrates food type, chips were the most consumed with $(64.2 \%)$ of the respondents indicating that they consumed them on a weekly basis. This could be attributed to the fact the chips are easy to prepare and carry to school. The second most consumed carbohydrates in the same category was Ugali with more than half (53.3\%) of the respondents and this could also be due to the fact that it is also easy to prepare. Rice came third with $(51.7 \%)$ and chapatti fourth with $(50.8 \%)$ of the respondents indicating consuming them weekly. Nearly one third (30\%) of the respondent indicated that they never consumed yams at any given time. This could be because yams are not easily available, they take long to cook and also they were traditionally consumed by the low income earners in the society and by some certain communities in Kenya, therefore its acceptance as a staple food by other communities has not yet fully taken place.

Fig 2 A Bar Graph Showing the Frequency Consumption of Carbohydrates by respondents

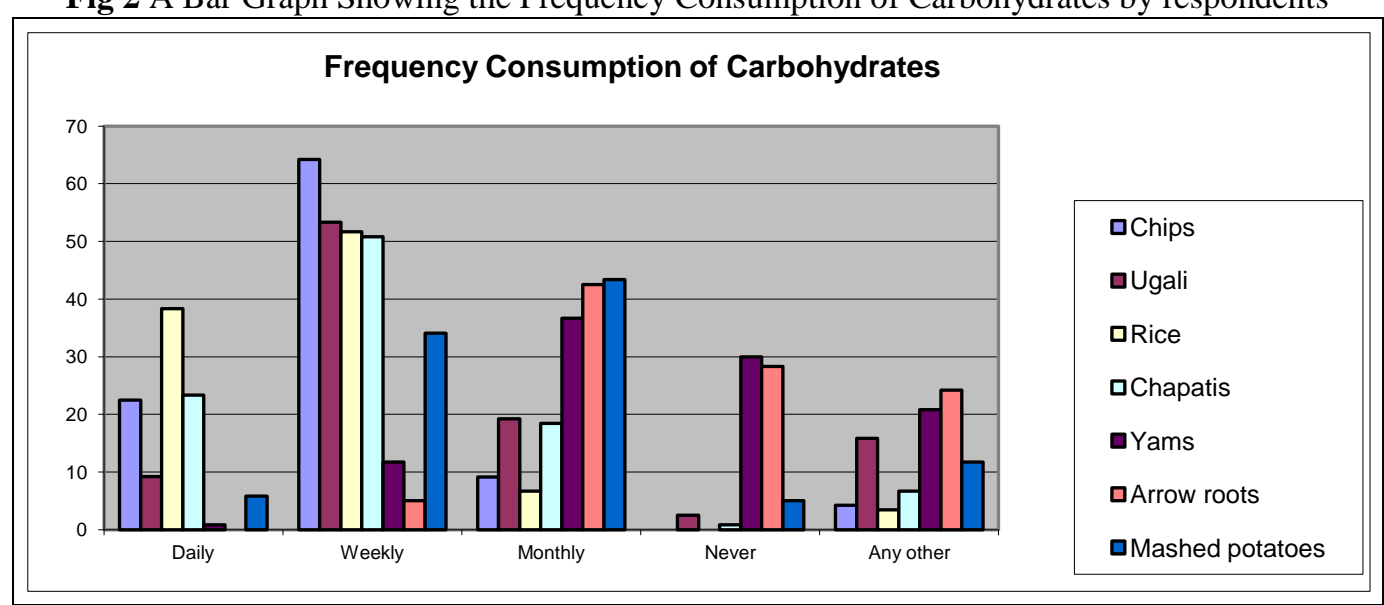

\subsubsection{Frequency Consumption of fats}

Fats provide the body with energy therefore it was necessary to find out the frequency of its consumption. The findings revealed that most of the fats were consumed on a daily basis with butter/margarine having the highest number $(65.0 \%)$ of the respondents. This could be due to the fact that they consume bread and butter/margarine daily. One third of the respondent (33.3\%) and 32.5\%) consumed peanut butter and cheese on a daily basis respectively and this could be because peanut butter and cheese are not very popular with respondent as compared butter/margarine also their tastes may not be appealing to the respondents. Only a small percentage $(2.5 \%)$ of the respondents indicated no consumption of butter/margarine this could be due to health reasons or taste preference. 
Fig 3: A Bar Graph Showing the Frequency Consumption of Fats by Respondents

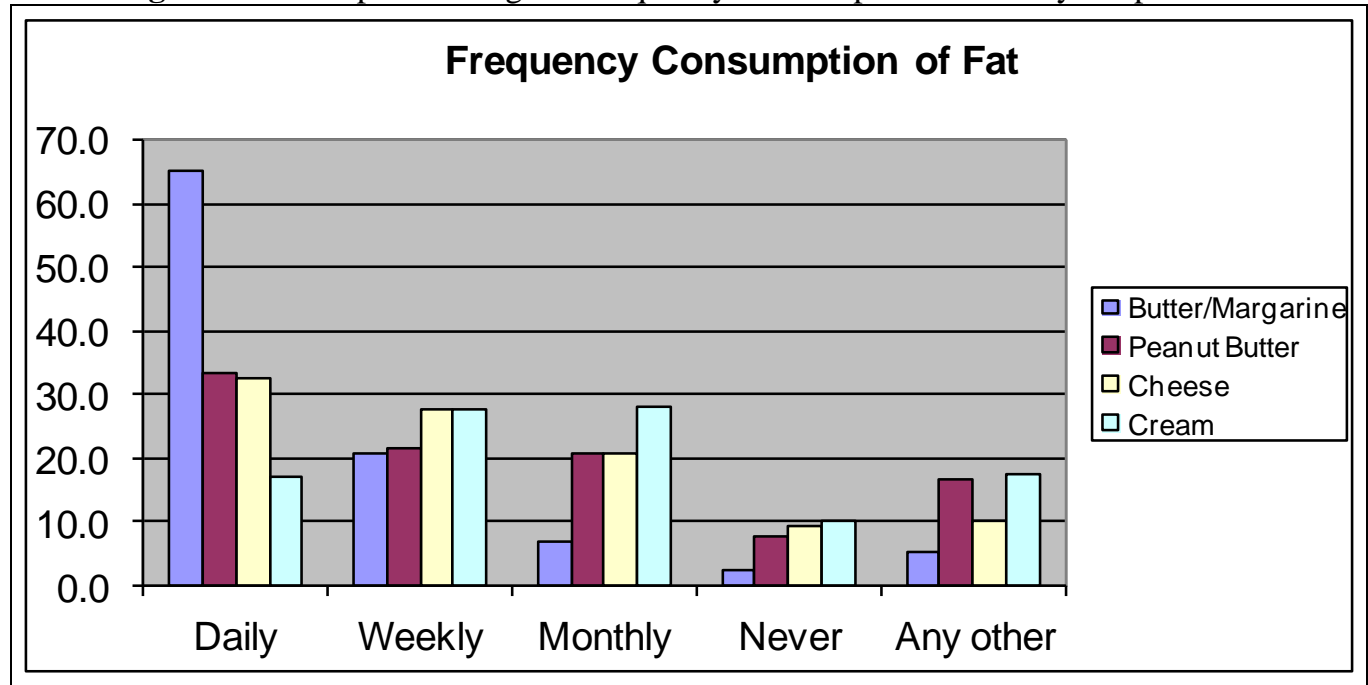

\subsubsection{Frequency Consumption of fruits}

Fruits provide the body with vitamins; hence it was necessary to find out how often they were consumed by the respondents. According to the findings, most of the fruits were consumed on a daily basis with bananas having the highest percentage $(47.5 \%)$ of the respondents. The distribution for consumption of all the fruits on a weekly basis was moderate with over one third (over 30\%) of the respondents indicating consuming them. See fig 4 below. The daily consumption of fruits could be as a result of their availability and low cost.

Fig 4. A Bar Graph Showing the Frequency Consumption of Fruits by Respondents

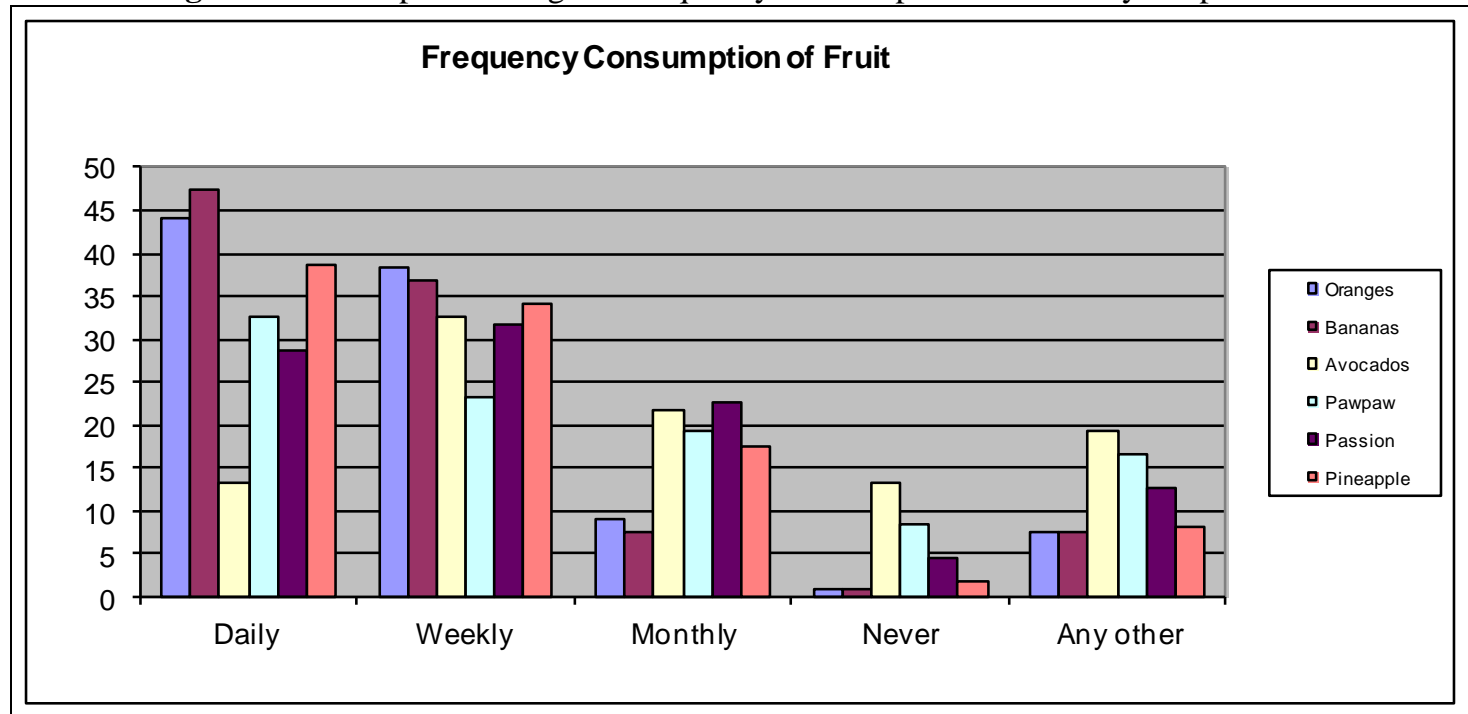

\subsubsection{Frequency Consumption of vegetables}

Vegetables provide the body with roughage and vitamins. It was therefore necessary to find out the pattern of consumption by respondents. Most of the vegetables were consumed more on a weekly basis than daily or monthly with three types of vegetables being consumed by over half (50\%) of the respondents.

These are cabbage and sukumawiki (50.9\%) each and spinach (50.0\%).

This could be due to their availability low cost and they are easy to cook. Cowpeas leaves had the lowest numbers of respondents in the daily $(66 \%)$ and weekly $(21.7 \%)$ categories of consumption and the highest number of respondent in the never $(22.5 \%)$ and any other categories of consumption. This is due to the fact that cow pea leaves are not readily available and they take a long time to cook as opposed to sukumawiki, cabbage and spinach. 
Fig 5 A Bar Graph showing the Frequency Consumption of Vegetables by respondents

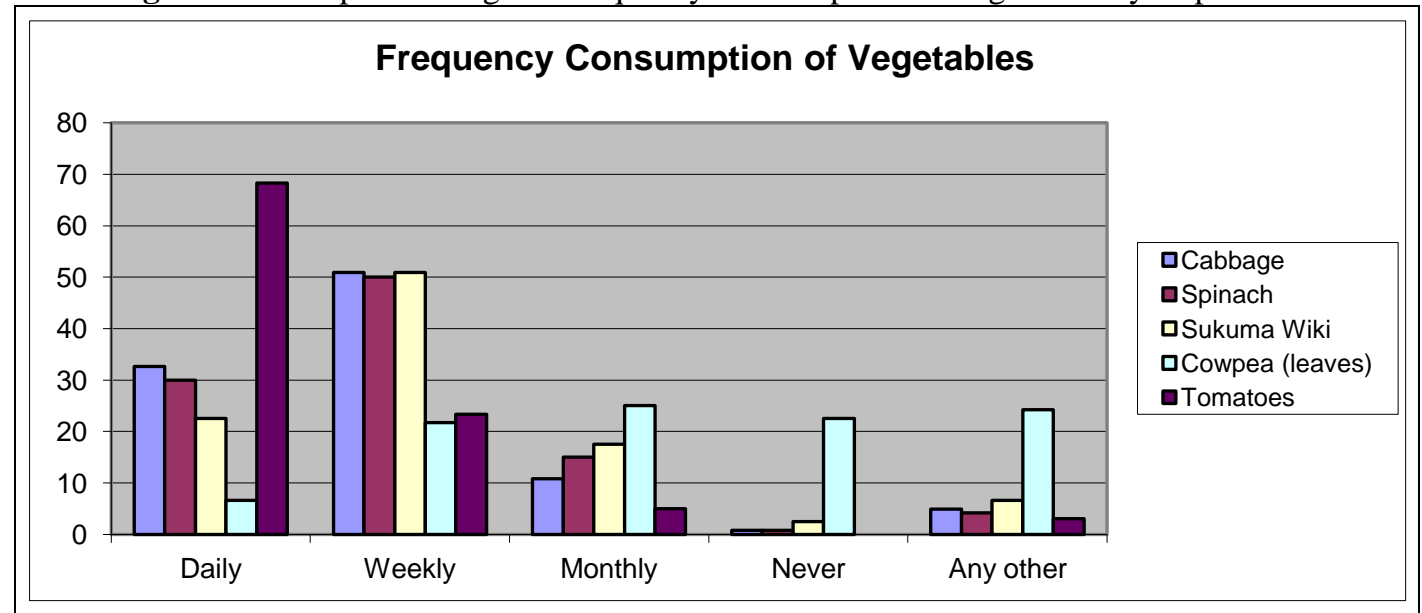

\subsection{Relationship between Dietary patterns and Obesity}

The null hypothesis that there is no significant relationship between obesity and dietary patterns was rejected. Hence therefore we conclude that there is a significant relationship between obesity and dietary patterns of pre-adolescents. On further testing the regression analysis results revealed that eating three times a day and eating any time were positively correlated with obesity. However, the relationship between these variables and obesity was not significant as indicated on Table 8.

Table 10: Coefficients of Eating Habits

\begin{tabular}{|c|c|c|c|c|c|}
\hline \multirow{2}{*}{ Model } & \multicolumn{2}{|c|}{ Unstandardized Coefficients } & \multicolumn{3}{|c|}{ Standardized Coefficients } \\
\hline & $\mathrm{B}$ & Std. Error & Beta & $\mathrm{t}$ & Sig. \\
\hline Constant & 29.646 & 2.026 & & 14.635 & .000 \\
\hline Eats thrice & .330 & 1.285 & .059 & .257 & .798 \\
\hline Eats anytime & .779 & 1.331 & .136 & .585 & .561 \\
\hline Skipping meals & -2.016 & .701 & -.337 & -2.877 & .006 \\
\hline Eat between meals & 1.203 & .724 & .213 & 1.661 & .102 \\
\hline Consume Sweet foods & -.305 & 1.430 & -.026 & -.213 & .832 \\
\hline
\end{tabular}

Skipping meals had a very significant relationship with obesity. The t-statistic of -2.88 was significant at the $5 \%$ significance level. This implied that an obese person could reduce their BMI by 2.0 points by skipping meals. On the other hand, eating between meals was likely to increase obesity by 1.2 points. Eating between meals is positively correlated with obesity and this result was significant at the $10 \%$ significance level. This finding concurs with Williams (1989) who pointed out that continued nibbling of food between meals was associated with obesity.

\section{Discussion}

The type of snack consumed highly affects the basal metabolic rate and nutrient content level of an individual. Pre-adolescents tend to think that these foods are more superior to fresh homemade foods hence their preferences. [13], pointed out that intake of energy, involving excessive consumption of refined sweets, sugars, refined foods and fats was a common practice that predisposed the individual to obesity. These findings revealed that the type of snacks consumed by the respondents were mainly carbohydrate, fat, and refined foods, sweets and sugars, hence this could predispose children to obesity.

Data collected indicated that $55.8 \%$ of the respondents ate between meals and the type of snacks consumed were carbohydrates, fat and refined foods. According to [14], intake of energy involving, excessive consumption of refined foods and fats was a common practice that predisposed the individual to obesity. This is true with the findings of this study. Consuming sweet foods, though exhibiting a negative relation with obesity was not significant at the 5\% significance level. Regression Analysis results showed that eating food three times a day and eating any time were positively correlated with obesity. Skipping meals had a very significant relationship with obesity. The t-statistic of -2.88 was significant at $5 \%$ significant level. This implied that an obese person could reduce their BMI by 2.0 points by skipping meals. On the other hand, eating between meals was positively correlated with obesity and the result was significant at $10 \%$ significant level. 


\subsection{Conclusions}

\section{Conclusions And Recommendations Conclusion}

The outlined findings show that a variety of foods were consumed in between meals by pre-adolescents with the carbohydrates, fat and proteins having the highest percentage. Snacks were also popular among preadolescent with most nibbling in between meals. Media also has an influence on the food choices of the preadolescents making them want to try almost all the food items they see in the commercial advertisements.

\subsection{Recommendations}

Based on the findings, it is recommended that snacks that are popular among pre-adolescent and are poor in nutritional value should be fortified with nutrients that are lacking, nutrition education should be given to pre-adolescents so that they can make wise choices in selection of snacks and meals, schools should establish a compulsory lunch programme where a balanced meal is provided and all children enroll for it. Also schools should provide the outside catering services with a standard menu to be followed.

\subsection{Suggestions For Further Research}

A study can be conducted on the effects of obesity on the health of Pre- Adolescents. Since this study was carried out in day private primary schools in Nairobi. A comparative study on the same topic could be done on boarding private primary schools in Nairobi.

\section{References}

[1]. Dietz, W.H. (1988). Childhood obesity; Obesity and Weight Control. Obesity Research Centre, New York.

[2]. Eleanor, N.T. and Frances S.S. (1988). Nutrition Concepts and Controversies, $\left(4^{\text {th }}\right.$ Ed.). New York: West Publishing Company

[3]. Robinson, C.H., Lawler, M.R., Chenoweth, W.L and Garwick, A.E. (1986). Normal and Therapeutic Nutrition, $\left(17^{\text {th }}\right.$ Ed.). New York: Macmillan Publishing Company.

[4]. Gail, Z. and Marie, A.B (1996). Personal Nutrition ${ }_{2}\left({ }^{\text {rd }}\right.$ Ed.) New York.West Publishing Company.

[5]. Kotani, K. (1997). Two decades of annual medical examinations in Japanese obese children grow into obese adults? International Journal of Obesity and related metabolic disorders, 21 (10): 912 - 921

[6]. Williams, S.R. (1989). Nutrition and Diet Therapy,_(6 ${ }^{\text {th }}$ Ed.) BOSTON. TORONTO. Times Mirror/ Mesby College Publishing Company.

[7]. Twahir. (2000.) Obesity becoming a major problem. Daily Nation.Pg.23

[8]. Barasi, E.M.(1997). Human Nutrition. A Health Perspective Arnold International Students Edition. Oxford Press, Inc.

[9]. Taras, H.L. and Gage, M. (1995). Advertised foods on children's television. Archives of Pediatrics and adolescent medicine. 149: $649-652$

[10]. Tansey G., Worsley T. (1995) The Food System: a Guide London, Earthscan

[11]. Buisson, D.H. (1992) .Consumer food choices for the 2000s - The impact of social and marketing trends. Paper presented at the CSIRO Food Industry Conference, Adelaide.

[12]. Astrup, A. (1996). Food and eating habits. Background paper prepared by international Obesity Task Force (IOTF) Food and Eating Habits Subgroup.

[13]. Popkin, B.M. (1995). A review of dietary and environmental correlates of obesity with emphasis on developing countries. Obesity research, 3 (Suppl.2): 145S - 153S.

[14]. Latham, M.C. (1997). Human Nutrition in Developing World.FAO Italy. 